\title{
PEMBUATAN PERMEN JAMU CEKOK DAN KARAKTERISTIK YANG DIHASILKAN
}

\section{THE MAKING OF HERBAL SQUEEZED CANDY AND THE PRODUCING CHARACTERISTICS}

\author{
Sri Hidayati ${ }^{1 凶}$, Fibra Nurainy $^{1}$, Dyah koesoemawardani ${ }^{1}$ dan $_{\text {Mierinda Sefriadi }}{ }^{1}$ \\ ${ }^{1}$ Jurusan TeknologiHasilPertanian, FakultasPertanian, Universitas Lampung \\ ${ }^{\otimes}$ Komunikasi Penulis, email: srihidayati.unila@gmail.com \\ DOI:http://dx.doi.org/10.23960/jtep-l.v10i1.57-63
}

Naskah ini diterima pada 25 November 2020; revisi pada 9 Februari 2021;

disetujui untuk dipublikasikan pada 8 Maret 2021

\begin{abstract}
Medicinal herbs are stimulants made from various types of medicinal plants which function to stimulate children's appetite. One of the drawbacks of herbal punching is that it is bitter in taste and the aroma is less favorable so that it takes effort to make herbal punching a preferred product, namely by processing the herbs into candy. The purpose of this study was to obtain the concentration of agar flour as a gelling agent for the best sensory and chemical properties of the herbal squeezed candy. The treatments were gelatin concentrations of $1 \%, 1.2 \%, 1.4 \%$, $1.6 \%, 1.8 \%$ and $2 \%$. The study used a Complete Randomized Block Design (CRBD) and further test of the Least Significant Difference. The results showed that the best agar concentration was $1.6 \%$ with candy products which had an aroma score of 3.73 (not typical of herbal medicine), a texture score of 4.16 (chewy), a taste score of 3.66 (sweet) and 80.\% of children's panelists said they liked it. The herbal medicine jelly candy has water content of $12.61 \%$, reducing sugar of 9.48 , ash content of $8.96 \%$. All meet SNI except ash content.
\end{abstract}

\section{Keywords: herbal punching, jelly candy, jelly flour}

\begin{abstract}
ABSTRAK
Jamu cekok merupakan stimulan yang dibuat dari berbagai jenis tanaman obat yang berfungsi untuk merangsang munculnya nafsu makan anak. Salah satu kelemahan jamu cekok adalah rasanya yang pahit dan aromanya kurang disukai sehingga diperlukan usaha untuk membuat jamu cekok menjadi produk yang disukai yaitu dengan mengolah jamu cekok menjadi permen. Tujuan penelitian ini adalah mendapatkan konsentrasi tepung agar-agar sebagai bahan pembentuk gel terhadap sifat sensori dan kimia permen agar-agar jamu cekok terbaik. Perlakuan yaitu konsentrasi agar-agar 1\%, 1,2\%, 1,4\%, 1,6\%, 1,8\% dan 2\%. Penelitian menggunakan Rancangan Acak Kelompok Lengkap (RAKL) dan uji lanjut Beda Nyata Terkecil. Konsentrasi agar-agar terbaik diperoleh pada 1,6\% dengan produk permen yang memiliki skor aroma tidak khas jamu dengan skor 3,73, tekstur kenyal dengan skor 4,16, rasa manis dengan skor 3,66 dan dan tingkat kesukaan anak mencapai 80\% dari populasi sampel. Berdasarkan SNI, permen memenuhi standar yaitu kadar air sebesar $12,61 \%$ dan gula reduksi sebesar 9,48,sedangkan untuk kadar abu yaitu 8,96\% tidak memenuhi standar.
\end{abstract}

Kata Kunci: jamu cekok, tepung agar-agar, permen

\section{PENDAHULUAN}

Jamu cekok merupakan jenis jamu dipercaya mampu merangsang nafsu makan pada anak dan membunuh cacing pengganggu. Disebut dengan cekok karena jamu tersebut diminumkan kepada anak dengan cara dipaksakan masuk kedalam mulut dengan mencekok agar jamu bisa masuk kedalam mulut. Hal itu disebabkan karena rasa dan aroma jamu yang pahit dan kurang disukai oleh anak anak (Kartika, 2012). Pembuatan jamu cekok menggunakan berbagai jenis empon empon seperti kunyit, temulawak, kedaung, lempuyang, kencur dan temu (Marni dan Ambarwati, 2015). Temulawak dan kunyit mengandung kurkuminoid dan minyak atsiri. 
Pada temulawak terdapat sekitar 1-2\% dan minyak atsiri sekitar 1-12\% yang berfungsi sebagai anti bakteria, anti kanker, antitumor serta mengandung antioksidan (Anand, 2007; Dermawaty, 2015). Minyak atsiri juga mengandung saponin, flavonoid, alkaloid dan tanin.

Banyak suku di Indonesia memanfaatkan temulawak dalam mengobati penyakit yang terkait dengan kardiovaskuler, sistem pencernaan, sindrom metabolik, urologi, sistem gerak, sistem pernafasan, dan kategori kewanitaan (Syamsudin et al., 2019). Jahe mengandung zat aktif zingiberin, gingerol yang berfungsi sebagai anti inflamasi, kamfena, sineol dan zingeron (Aryanta, 2019). Fungsi jahe sebagai peluruh keringat, kentut, dan bersifat mengurangi rasa mual dan keteganganan (Ware, 2017). Kencur mengandung senyawa seperti alkaloid dan flavonoid (Muhlisah dan Fauziah, 2011). Kandungan terpenoid (bisabolol, chamazulene) pada kencur berfungsi sebagai antiinflamasi dan antispasmodik (flavonoid, epigenin). Rimpang temu hitam mengandung sesquiterpene dan monoterpene yang berkhasiat untuk meningkatkan napsu makan dan dapat mengobati cacingan dan mengurangi lendir pada mukosa. Uji fitokimia pada ekstrak kasar rimpang temu hitam menunjukkan adanya senyawa flavonoid, saponin, tanin, dan terpenoid (Mustiariani, et al., 2017).

Pemanfaatan biji Kedawung untuk pengobatan pencernaan bermasalah seperti cacingan dan radang maupun kembung (Hadad et al, 1993). Senyawa betasitosterol dapat menurunkan lemak darah (Tisnadjaya et al, 2006). Rimpang lempuyang mengandung senyawa yang dapat mengobati masuk angin, sakit pencernaan dan meningkatkan nafsu makan. Kandungan sesquiterpenoid zerumbone yang memiliki aktivitas biologis sebagai penghambat kanker dan tumor (Chandra et al., 2003). Untuk meningkatkan penerimaan terhadap jamu cekok maka perlu dilakukan diversifikasi produk olahan jamu cekok menjadi makanan yang disukai anak anak seperti menjadi permen agar-agar. Salah satu pengental yang dapat digunakan dalam proses pembuatan permen adalah agar-agar. Alginat, agar dan karaginan adalah karbohidrat yang larut dalam air yang digunakan untuk mengentalkan (meningkatkan viskositas), dan membentukgel (jeli). Salah satu hidrokoloid yang memiliki kemampuan gel tinggi adalah agar agar (Neish et al, 2015). Pembuatan permen agar agar dari dari buah naga merah dilakukan oleh Shabrina (2016) dengan hasil terbaik pada konsentrasi agar agar 2\%. Penelitan bertujuan untuk mendapatkan konsentrasi agar optimal yang menghasilkan permen jamu cekok yang memiliki sifat organoleptikyang disukai dan sifat kimia yang dihasilkan.

\section{BAHAN DAN METODE}

Bahan berupa empon empon, bubuk agar-agar, gula, buah naga, aquades, larutan Luffschrool, KI $50 \%$, $\mathrm{H} 2 \mathrm{SO} 415 \%$, dan Na-thiosulfat $0,1 \mathrm{~N}$ yang digunakan untuk analisis gula.

\subsection{Pelaksanaan Penelitian}

Perlakuan yaitu konsentrasi agar agar pada 6 taraf yaitu 1, 1,2, 1,4, 1,6 1,8 dan 2\%. Proses pembuatan jamu dilakukan dengan mempersiapkan bahan baku jamu cekok yaitu menghaluskan bahan yaitu temulawak $80 \mathrm{~g}$, jahe $20 \mathrm{~g}$, kunyit $60 \mathrm{~g}$, kencur $40 \mathrm{~g}$, lempuyang emprit $30 \mathrm{~g}$, temu ireng $40 \mathrm{~g}$, kedawung $5 \mathrm{~g}$. Setelah halus kemudian ditambahkan 1 liter air hangat matang dan disaring. Selanjutnya proses pembuatan permen dilakukan dengan cara mencampur $250 \mathrm{ml}$ filtrat jamu cekok dicampur dengan sari buah naga merah $50 \mathrm{ml}$ dan gula pasir sebanyak $200 \mathrm{~g}$, dan ditambah konsentrasi agar yaitu $1 \%, 1,2 \%, 1,4 \%, 1,6 \%, 1,8 \%$ dan 2 . Adonan dipanaskan selama 15 menit sampai homogen sambil dilakukan pengadukan dan dicetak ke dalam loyang hingga mengeras. Setelah mengeras, diberi taburan tepung gula dan dicetak persegi panjang dengan ukuran $1 \times 2 \mathrm{~cm}$. Perlakuan dilakukan menggunakan Rancangan kelompok Acak Lengkap dalam 3 ulangan dan data dianalisis menggunakan analisis ragam dan dilakukan uji lanjut menggunakan Beda Nyata Terkecil. Pengamatan yang dilakukan yaitu uji sensoris terhadap warna, aroma, rasa, tekstur, dan penerimaan keseluruhan dan uji skoring. Pada uji kesukaan dengan uji hedonic dengan analisis data secara deskriptif dengan menyatakan suka atau tidak suka terhadap anak SD yang menjadi panelis. Hasil terbaik 
dilakukan analisis kadar air, gula reduksi dan kadar abu (Sudarmadji, 2000).

\section{HASIL DAN PEMBAHASAN}

\subsection{Warna}

Berdasarkan analisi data diperoleh bahwa terdapat pengaruh nyata dari perlakuan agar agar dan hasil uji lanjut BNT menunjukkan bahwa perlakuan konsentrasi agar dari $1 \mathrm{sd}$ 1,6\% kecuali pada konsentrasi agar 1,8 dan $2 \%$ (Tabel 1). Skor penilaian tingkat warna permen agaragar jamu cekok adalah 1 (sangat kecoklatan), 2 (coklat), 3 (sedikit merah kecoklatan), 4 (merah kecoklatan), 5 (merah hati). Skor nilai warna produk permen pada konsentrasi agaragar sebesar $1-2 \%$ adalah 2,08-3,83 yang berarti warna yang dihasilkan coklat, sedikit merah kecoklatan, dan merah kecoklatan.

Warna merupakan indikator yang penting dalam menentukan penerimaan konsumen terhadap kualitas suatu makanan (Chandrasekara et al., 2012). Warna merah kecoklatan pada permen agar-agar merupakan warna coklat alami yang timbul dari air jamu yang berwarna coklat muda sebagai bahan baku dengan penambahan buah naga merah. Semakin banyak penambahan konsentrasi agar-agar yang digunakan maka akan menyebabkan warna permen agar-agar menjadi pekat. Hasyim et al. (2015) melaporkan bahwa penambahan konsentrasi agar-agar dapat menurunkan nilai sensori pada warna permen jelly dari buah srikaya yang semakin rendah.

\subsection{Aroma}

Hasil penelitian menunjukkan bahwa konsentrasi agar- agar dengan konsentrasi yang berbeda berpengaruh nyata terhadap parameter aroma permen agar-agar jamu cekok. Uji BNT menunjukkan bahwa skor aroma permen dengan perlakuan konsentrasi agar 1,0\%, 1,2\%, $1,4 \%$, dan $1,6 \%$ tidak berbeda kecuali pada perlakuan agar agar 1,8\% dan 2,0\% (Tabel 2). Skor penilaian aroma permen agar-agar jamu cekok adalah 1 (sangat khas jamu), 2 (khas jamu), 3 (sedikit khas jamu), 4 (tidak khas jamu), 5 (sangat tidak khas jamu).

Pada penambahan konsentrasi tepung agaragar sebesar $1,0 \%, 1,2 \%, 1,4 \%$ dan $1,6 \%$ memperlihatkan skor aroma permen agar-agar jamu cekok dengan nilai skor tidak mengarah bau jamu. Sifat utama tepung agar-agar sebagai hidrokoloid mampu membentuk gel dalam pembuatan permen agar-agar jamu cekok. Gelasi pada asosiasi (ikatan silang) dari rantai-rantai polimer untuk membentuk jaringan tiga dimensi secara kontinyu dan air jamu cekok terperangkap didalam matrik gel membentuk struktur yang kaku, kokoh dan dapat meningkatkan ketebalan pada produk permen agar-agar sehingga aroma pada permen agaragar masih berbau jamu apabila konsentrasi penambahan tepung nya tinggi (Marseno, 1998).

\subsection{Tekstur}

Hasil analisis sidik ragam menunjukkan bahwa terdapat pengaruh yang signifikan pada perlakuan terhadap tekstur permen. Skor penilaian aroma permen agar-agar jamu cekok adalah 1 (sangat keras), 2 (keras), 3 (sedikit kenyal), 4 (kenyal), 5 (sangat kenyal). Uji Beda Nyata Terkecil (BNT) menunjukan bahwa skor tekstur dengan penambahan agar 1,6\% berbeda nyata dengan skor 4,16 (Tabel $3)$.

Hidrokoloid bersifat mengentalkan sehingga penambahan kadar hidrokoloid dapat meningkatkan ketebalan pada produk

Tabel 1. Warna Permen Agar-agar Jamu Cekok

\begin{tabular}{lc}
\hline Perlakuan & Nilai Tengah \\
\hline Konsentrasi Agar 1\% $\%, 83^{\mathrm{a}}$ \\
Konsentrasi Agar 1,2\% & $3,71^{\mathrm{a}}$ \\
Konsentrasi Agar 1,4\% & $3,7^{\mathrm{a}}$ \\
Konsentrasi Agar 1,6\% & $3,58^{\mathrm{a}}$ \\
Konsentrasi Agar 1,8\% & $2,3^{\mathrm{b}}$ \\
Konsentrasi Agar 2\% & $2,08^{\mathrm{b}}$ \\
\hline BNT 5 \% = 0,39 & \\
\hline
\end{tabular}


Tabel 2. Skor Aroma Permen Agar-agar Jamu Cekok

\begin{tabular}{cc}
\hline Perlakuan & Nilai Tengah \\
\hline Konsentrasi Agar 1,6\% $\%$ & $3,73 \mathrm{a}$ \\
Konsentrasi Agar 1,2 \% & $3,63 \mathrm{a}$ \\
Konsentrasi Agar 1,0\% & $3,53 \mathrm{a}$ \\
Konsentrasi Agar 1,4 \% & $3,46 \mathrm{a}$ \\
Konsentrasi Agar 1,8 \% & $2,50 \mathrm{~b}$ \\
Konsentrasi Agar 2\% & $2,45 \mathrm{~b}$ \\
\hline BNT 5 \% 0,38 & \\
\hline
\end{tabular}

Tabel 3. Skor Tekstur Permen Agar-agar Jamu Cekok

\begin{tabular}{cc}
\hline Perlakuan & Nilai tengah \\
\hline Konsentrasi Agar 1,6\% & $4,16 \mathrm{a}$ \\
Konsentrasi Agar 1,4\% & $3,88 \mathrm{~b}$ \\
Konsentrasi Agar 1,2\% & $3,81 \mathrm{~b}$ \\
Konsentrasi Agar 1,0\% & $3,71 \mathrm{~b}$ \\
Konsentrasi Agar 1,8 \% & $1,95 \mathrm{c}$ \\
Konsentrasi Agar 2\% & $1,58 \mathrm{~d}$ \\
\hline BNT 5 \%=0,34
\end{tabular}

Tabel 4. Skor Rasa Permen Agar-agar Jamu Cekok

\begin{tabular}{cc}
\hline Perlakuan & Nilai Tengah \\
\hline Konsentrasi Agar 1,6 \% & $3,66 \mathrm{a}$ \\
Konsentrasi Agar 1,0 \% & $3,55 \mathrm{a}$ \\
Konsentrasi Agar 1,4 \% & $3,20 \mathrm{~b}$ \\
Konsentrasi Agar 1,2\% & $3,15 \mathrm{~b}$ \\
Konsentrasi Agar 1,8 \% & $2,60 \mathrm{c}$ \\
Konsentrasi Agar 2\% & $2,51 \mathrm{c}$ \\
\hline BNT 5 \% = 0,32
\end{tabular}

Keterangan : Nilai tengah yang diikuti dengan huruf pada kolom yang sama dinyatakan tidak berbeda menurut uji BNT pada taraf $5 \%$

makanan (Piccone et al., 2011). Penelitian Shabrina (2016), yang menyatakan bahwa penambahan konsentrasi agar-agar yang semakin banyak menyebabkan permen jelly semakin keras dan teksturnya menjadi mudah patah dan tidak kenyal. Hal ini disebabkan karena sifat dari agar-agar yang membentuk tekstur yang keras bila dibandingkan dengan karaginan tepung agar-agar memiliki viskositas yang lebih rendah sehingga pada penambahan konsentrasi agar-agar yang tinggi dapat semakin meningkatkan kekerasan gel menjadi rapuh pada produk permen jelly (Marseno, 1988).

\subsection{Rasa}

Hasil analisis sidik ragam menunjukkan bahwa konsentrasi tepung agar- agar berpengaruh nyata terhadap parameter rasa permen agaragar jamu cekok. Uji lanjut terlihat jika skor rasa permen pada perlakuan 1,0\% tidak siknifikan dibandingkan dengan perlakuan lainnya (Tabel 4).

Skor penilaian rasa permen agar-agar jamu cekok adalah 1 (sangat tidak manis), 2 (tidak manis), 3 (sedikit manis), 4 (manis), 5 (sangat manis). Rasa merupakan salah satu faktor yang sangat penting dalam peerimaan konsumen. Shabrina (2016) memperlihatkan kecenderungan yang sama bahwa kesukaan panelis terhadap rasa permen jelly buah naga merah semakin menurun dengan semakin bertambahnya konsentrasi tepung agar-agar yang digunakan. Kesukaan panelis terhadap rasa permen jelly buah naga merah semakin menurun dengan semakin bertambahnya konsentrasi tepung agar-agar yang digunakan karena pada kadar tepung agar-agar yang tinggi cenderung dihasilkan gel yang kokoh. Efek gelasi yang tinggi diperkirakan dapat menutupi rasa dari permen jelly karena tebalnya permen yang 
dihasilkan sehingga menutupi rasa dan aroma asli bahan yang ditambahkan. Sesuai dengan pernyataan Piccone et al., (2011), yang menyatakan bahwa peningkatan kadar hidrokoloid pada akan mempertebal produk.

\subsection{Uji Hedonik}

Uji hedonik dilakukan dengan memberikan sample kepada anak-anak SD kelas 1 dengan umur 5-6 tahun. Penilaian hanyak berdasarkan pilihan suka atau tidak suka. Pada Tabel 5 menunjukkan dari 50 panelis permen yang paling disukai adalah permen jelly dengan penambahan konsentrasi agar-agar 1,6\% dengan persentase kesukaan $80 \%$ sedangkan permen yang paling tidak disukai terjadi pada konsentrasi penambahan agar-agar sebesar $2,0 \%$. Hal ini disebabkan karena penambahan tepung agar-agar 1,6\% memiliki warna dengan skor 3,70 (merah kecoklatan), aroma 3,73 (tidak khas jamu), tekstur 4,16 (kenyal), dan rasa 3,66 (manis) sehingga paling disukai oleh panelis (Tabel 5). Penambahan tepung agar-agar yang terlalu sedikit menghasilkan permen jelly yang tidak kenyal dan sulit dalam proses pencetakan yaitu penggulungan. Peningkatan agar agar menghasilkan permen jelly yang keras dan dalam proses pencetakan yaitu penggulungan, permen jelly menjadi patah dan hancur.

\subsection{Penentuan Perlakuan Terbaik}

Hal ini berdasarkan hasil nilai uji sensori dengan parameter aroma, rasa, dan uji hedonik yang meliputi tingkat kesukaan secara keseluruhan panelis terhadap permen agar-agar jamu cekok (Tabel 6).

Pemilihan perlakuan terbaik ditentukan berdasarkan narasi banyaknya tanda bintang pada masing-masing parameter. Tanda bintang menunjukkan skor penilaian yang tinggi dari panelis untuk setiap atribut sensori yang di uji. Untuk parameter aroma perlakuan terbaik ada perlakuan agar $1,0 \%, 1,2 \%, 1,4 \%$, dan $1,6 \%$, sedangkan rasa pada perlakuan agar $1,0 \%$ dan 1,6\%. Pada uji hedonik perlakuan terbaik penambahan tepung agar-agar didapatkan pada konsentrasi 1,6\% dengan hasil persentase kesukaan paling tinggi dibandingkan dengan perlakuan lain nya. Berdasarkan perolehan tanda bintang tersebut maka perlakuan terbaik ada pada perlakuan $D$ yaitu penambahan tepung agar-agar sebanyak 1,6\%. Permen agar-agar jamu cekok terbaik kemudian dianalisis lebih lanjut terhadap sifat kimia yang meliputi kadar air, kadar gula reduksi, dan kadar abu.

\subsection{Analisis Kimia Permen Agar-agar Jamu Cekok}

Analisis kimia yang akan diuji pada permen agaragar meliputi kadar air, kadar gula reduksi, dan kadar abu (Tabel 7). Berdasarkan hasil penelitian, kadar air permen agar-agar jamu cekok mempunyai nilai rata-rata sebesar 12,61\%. Nilai kadar air lebih rendah dibandingkan dengan kadar maksimal yang

Tabel 5. Hasil Uji Hedonik Permen

\begin{tabular}{|c|c|c|c|c|c|c|c|c|c|c|c|c|}
\hline \multirow[b]{3}{*}{ Nama } & & & \multicolumn{10}{|c|}{ Konsentrasi Tepung Agar-agar } \\
\hline & \multicolumn{2}{|c|}{$A(1 \%)$} & \multicolumn{2}{|c|}{ B $(1,2 \%)$} & \multicolumn{2}{|c|}{$\mathrm{C}(1,4 \%)$} & \multicolumn{2}{|c|}{ D $(1,6 \%)$} & \multicolumn{2}{|c|}{$E(1,8 \%)$} & \multicolumn{2}{|c|}{ F (2\%) } \\
\hline & $S$ & TS & $S$ & TS & $S$ & TS & $\mathrm{S}$ & TS & $S$ & TS & $\mathrm{S}$ & TS \\
\hline \multirow{2}{*}{ Jumlah } & 3 & 1 & 2 & 21 & 37 & 1 & $40^{*}$ & 10 & 26 & 24 & 19 & 31 \\
\hline & 3 & 7 & 9 & & & 3 & & & & & & \\
\hline \multirow{2}{*}{$\%$} & 6 & 3 & 5 & 42 & 74 & 2 & 8 & 20 & 52 & 48 & 38 & 62 \\
\hline & 6 & 4 & 8 & & & 6 & 0 & & & & & \\
\hline
\end{tabular}

Keterangan : * Penentuan parameter yang paling disuka, S= Suka, TS (Tidak suka)

Tabel 6. Rekapitulasi Pemilihan Perlakuan Terbaik

\begin{tabular}{lcccccc}
\hline Parameter & A & $\mathbf{B}$ & $\mathbf{C}$ & $\mathbf{D}$ & $\mathbf{E}$ & $\mathbf{F}$ \\
& $\mathbf{( 1 , 0 \% )}$ & $\mathbf{( 1 , 2 \% )}$ & $\mathbf{( 1 , 4 \% )}$ & $\mathbf{( 1 , 6 \% )}$ & $\mathbf{( 1 , 8 \% )}$ & $\mathbf{( 2 , 0 \% )}$ \\
\hline Aroma & $3,53 \mathrm{a}^{*}$ & $3,63 \mathrm{a}^{*}$ & $3,46 \mathrm{a}^{*}$ & $3,73 \mathrm{a}^{*}$ & $2,50 \mathrm{~b}$ & $2,45 \mathrm{~b}$ \\
Rasa & $3,55 \mathrm{a}^{*}$ & $3,15 \mathrm{~b}$ & $3,20 \mathrm{~b}$ & $3,66 \mathrm{a}^{*}$ & $2,60 \mathrm{c}$ & $2,51 \mathrm{c}$ \\
Uji Hedonik & $66 \%$ & $58 \%$ & $74 \%$ & $80 \% *$ & $52 \%$ & $38 \%$ \\
\hline
\end{tabular}

Keterangan : ${ }^{*}=$ Perlakuan terbaik pada parameter tersebut 
Tabel 7. Nilai Komponen Kimia Permen

\begin{tabular}{cccc}
\hline Ulangan & Kadar Air \% & Kadar Gula Reduksi \% & Kadar Abu \% \\
\hline 1 & 12,73 & 7,04 & 9,70 \\
2 & 10,80 & 12,30 & 7,06 \\
3 & 14,30 & 9,10 & 9,32 \\
\hline Rata-rata & 12,61 & 9,48 & 8,69 \\
\hline SNI & Max 20\% & Max 25 \% & Max 3\% \\
\hline
\end{tabular}

ditentukan SNI 3547.2-2008 yaitu 20\%, yang berarti produk permen agar-agar yang dihasilkan lebih bagus karena akan lebih tahan serangan mikroorganisme. Kadar air sering dikaitkan dengan merupakan parameter pangan untuk melihat daya awet produk (Sundari et al., 2015) karena air dibutuhkan untuk pertumbuhan mikroorganisme. Kadar air yang terkandung dalam permen agar-agar jamu cekok juga dipengaruhi oleh gula yang tinggi. Konsentrasi gula yang tinggi akan menyebabkan terjadinya air didalam bahan keluar akibat proses penetrasi gula. Adanya gula menyebabkan proses pemasakan lebih lama sehingga menurunkan kadar air (Gaman and Sherrington, 1981). Kadar gula reduksi permen ini yaitu 9,48\% dan lebih rendah dibandingkan dengan batas maksimal kadar gula reduksi yang ditentukan SNI 3547.2-2008 yaitu 25\%. Metode pengukuran dengan menggunakan metode Luff Schrool.

Kadar abu permen yaitu 8,69\% dan lebih tinggi dibandingkan dengan kadar maksimal yang ditentukan SNI 3547.2-2008 yaitu 3\%. Yani dan Indah (2006), melaporkan bahwa rumput laut memiliki kandungan mineral yang cukup tinggi. Liem (2013) menyatakan bahwa kadar abu rumput laut sekitar 17,69-19,70\% sedangkan hasil penelitian Safia et al, (2020) kadar abu rumput laut berkisar $43,49 \pm 9,23 \%$ tergantung lingkungan bahan.

\section{KESIMPULAN DAN SARAN}

Berdasarkan hasil penelitian dapat disimpulkan bahwa pada proses pembuatan permen jamu cekok yang terbaik yaitu menggunakan konsentrasi agar sebesar 1,6\% dengan hasil skor organoleptikyaitu aroma sebesar 3,73 (tidak khas jamu), skor tekstur 4,16 (kenyal), rasa 3,66 (manis) dan $80 \%$ panelis anak-anak menyatakan suka, kadar air sebesar $12,61 \%$, gula reduksi sebesar 9,48, kadar abu 8,96\%. Semua memenuhi uji memenuhi standar SNI kecuali kadar abu.

\section{DAFTAR PUSTAKA}

Anand, P. 2007. Bioavailability of Curcumin: Problems and Promises. $J \mathrm{Mol}$ Pharmaceutics. 4(6): 807-18.

Aryanta., I.W.R. 2019. Manfaat Jahe Untuk Kesehatan. E-Jurnal Widya Kesehatan.1(2): 39-43.

Chandra. K., Mcintosh, G.H., Ian, R.R., and Graham, J. 2003. Antitumor Activity of Extract of Zingiber Aromaticum and its Bioactive Sesquiterpenoid Zerumbone. Nutrition and Cancer. 45(2):218-225.

Chandrasekara, A., M. Naczk and F. Shahidi. 2012. Effect of Processing on the Antioxidant Activity of Millet Grains. Journal of Food Chemistry. 133: 1-9.

Dermawaty, D.E. 2015. Potential Extract Curcuma (Curcuma xanthorrizal, Roxb) as Antibacterials. J MAJORITY. 4(1): 1-11.

Gaman, P. M and Sherrington, K. B. 1981. The Science of Food: Introduction to Food Science, Nutrition and Microbiology (Third Edition). Pergamus Press. New York, USA.

Hadad, E.A.W., Taryono, S.D., Udin, M.S.D., dan asita. 1993. Pemanfaatan Meniran dan Kedawung dalam obat tradisional di Jawa Barat. Warta Tumbuhan Obat Indonesia. Indonesia. Vol (No): halaman

Hasyim, H., Rahim, A., dan Rostiati. 2015. 
Karakteristik Fisik Kimia dan Organoleptik Permen Jelly dari Sari Buah Srikaya pada Variasi Konsentrasi AgarAgar. Agrotekbis, 3(4): 463-474.

Kartika, S.A. 2012. Eksistensi Jamu Cekok di Tengah Perubahan Sosial (Studi di Kampung Dipowinatan, Kelurahan Keparakan, Kecamtan Mergangsan,Yogyakarta) [Skripsi]. Universitas Negeri Yogyakarta. Yogyakarta.

Liem , Z.A. 2013. Kandungan Proksimat dan Aktivitas Antioksidan Rumput Laut Merah (Euchema cottonii) di Perairan Kupang Barat [Tesis) Salatiga (ID): Universitas Kristen Satya Wacana.

Marni., dan Ambarwati, R. 2015. Khasiat Jamu Cekok Terhadap Peningkatan Berat Badan pada Anak. Jurnal Kesehatan Masyarakat. Vol (No):halaman

Marseno, D. W. 1998. Kimia dan Teknologi Karbohidrat. Hand Out Mata Kuliah Ilmu dan Teknologi Pangan. Universitas Gadjah Mada. Yogyakarta . diganti atau Buang

Muhlisah dan Fauziah. 2011. Tanaman Obat Keluarga. Penebar Swadaya. Jakarta.

Mustariani, B.A.., Izuddin, A., Hasyim, D.M., dan Batubara, I. 2017. Uji Toksisitas dan Aktivitas Antimakan Ekstrak Rimpang Temu Hitam (Curcuma Aeruginosa Roxb). Jurnal Farmasetis. 6(1): 1-8.

Neish, I., Salling, P., Aregger, P., and Klose, J. 2015. Carrageenan and Agar Official Programme Partner Indonesia, Beyond The Land of Cottonii and Gracilaria. Switzerland Global Enterprise, Zurich.

Piccone, P., Simon L., Rastelli., and Pittia, P. 2011. Aroma Release and Sensory Perception of Fruit Candies Model Systems. Department of Food Science. University of Teramo, Italy

Safia, W, Budiyanti, dan Musrif. 2020. Kandungan nutrisi dan senyawa bioaktif rumput laut (Euchema cottonii) dengan metode rakit gantung pada kedalaman berbeda. Jurnal Pengolahan Hasil Perikanan Indonesia. 23(2): 261-271.

Shabrina, A. 2016. Pengaruh Konsentrasi Tepung Agar-Agar terhadap Sifat Sensori, Kimia dan Mikrobiologi Permen Jelly Buah Naga Merah (Hylocereus polyrhizus) Selama Penyimpanan Pada Suhu Ruang [Skripsi]. Universitas Lampung. Lampung.

Standar Nasional Indonesia (SNI). 2008. Standar Nasional Indonesia Kembang Gula- Bagian 2: Lunak. SNI 3547.2-2008. Badan Standarisasi Nasional.Indonesia.

Sudarmadji, S. 2000. Analisis Bahan Makanan dan Pangan. Penerbit Liberty.Yogyakarta.

Sundari, D., Almasyhuri dan Lamid, A. 2015.Pengaruh Proses Pemasakan Terhadap Komposisi Zat Gizi Bahan Pangan Sumber Protein. Media Litbangkes. 5(4) : 235-242.

Syamsudin, R.A.M.R., Perdana, F., Mutiaz, F.S., Galuh, V., Rina, A.P.A., Cahyani, Sri Aprilya, N.D., Yanti, R., dan Khendri, F. 2019. Temulawak Plant (Curcuma Xanthorrhiza Roxb) as A Traditional Medicine. Jurnal Ilmiah Farmako Bahari. 10(1): 51-65

Tisnadjaja, D., Hidayat, S.L., Sumirja, S dan Simanjuntak, P. 2006. Pengkajian Kandungan Fitosterol pada Tanaman Kedawung (Parkia roxburgii G Don.). Biodiversitas . 7(1): 21-24.

Ware, M. 2017. Ginger: Health Benefits and Dietary Tips. https:// www.medicalnewstoday.com /articles/ 265990.php. (diakses tanggal 15 September 2019).

Yani, H., dan Indah. 2006. Karakteristik Fisika Kimia Permen Jelly dari Rumput Laut Eucheuma spinosum dan Eucheuma cottonii [Skripsi]. Bogor: Institut Pertanian Bogor. Bogor. 